\title{
SABER SOCIAL e RURALIDADES: um olhar sobre o papel da mulher.
}

\author{
Halline Mariana Santos Silva* \\ Igor José da Silva *1
}

\begin{abstract}
This paper presents some reflections on the actors of the rural areas and the production of meaning of the new ruralities, in the context of modernization, in the region of south-west Goiás, taking the woman's role as a background in this process. In this work it was emphasized the role that women have been fulfilling in the construction of ruralities and whether, in the social rural spaces, it can be noticed the forms of resistance to "modernization".
\end{abstract}

Key-words: ruralities, modernization, woman's role, resistance, social knowledge.

Resumo: O presente estudo apresenta algumas reflexões sobre os atores do meio rural e a produção de sentido de novas ruralidades, no contexto de modernização, na região do sudoeste goiano, tendo como pano de fundo o papel da mulher nesse processo. Neste trabalho buscou-se destacar o papel que as mulheres têm desempenhado na (re) construção das ruralidades e se, nos espaços sociais rurais pode ser percebidas formas de resistência à "modernização".

Palavras chave: ruralidades, modernização, papel da mulher, resistência, saber social.

\section{Introdução}

Durante a construção de uma história e de uma Sociologia Rural no Brasil, o sujeito em questão foi quase sempre a modernização, a implementação de técnicas e tecnologias, o próprio sujeito, quando constituído como objeto de estudo, o é na condição de sujeito da modernização. Há ainda pouca pesquisa sobre os sujeitos reais do campo, seus modos de vida ${ }^{2}$, suas culturas, e principalmente suas estratégias de resistir ao que afeta sua modalidade de vida, bem como, o saber social que estes atores possuem. Sujeitos invisiveis, de culturas opacas expostas a estudos sobre o campo e o seu contexto de modernização - a pesquisa, nesse sentido, assumiu durante anos uma atitude impositiva e retratou uma visão parcial e unilateral dessa realidade - omitindo que não existe hegemonia no espaço social seja ele rural ou não, visto que o conflito se estabelece

\footnotetext{
* Pedagoga, Mestre em Educação UFG e Doutoranda em Educação UnB, [e-mail: hallinemariana@ hotmail.com]

* Engenheiro Agrônomo, Especialista em Agricultura Familiar Camponesa e Educação do Campo, atualmente consultor do Ministério do Desenvolvimento Agrário -MDA [Igor.silva@consultor.mda.gov.br]

${ }^{2}$ Sobre o modo de vida do sujeito rural (o caipira), ver os significativos estudos de Antonio Candido em Os parceiros do Rio Bonito (1979).
} 
em qualquer lugar onde haja propriedade privada e um Estado comprometido com interesses divergentes.

Estudos acadêmicos vêm sendo desenvolvidos, no sentido de compreender a redefinição da relação campo cidade, porém, estes estudos em sua maioria, tendem a manter os sujeitos do campo, invisíveis, principalmente quando se trata do respeito à participação das mulheres nesse processo. É preciso dar voz às vivências femininas que ocorrem no campo, pelo fato de que essas vozes compõem as ruralidades.

Neste artigo, apresentam-se algumas observações sobre o papel da mulher em novos processos que estão ocorrendo no meio rural. Identifica quais as estratégias que vêm sendo adotadas pelas famílias que ainda vivem no ‘campo' para a dinamização e a manutenção de modos de viver o/no meio rural. Longe de pretender esgotar o assunto, mas no intuito de suscitar futuras discussões. Busco conhecer e (re)conhecer o papel da mulher assentada, nos novos processos em curso que vêm "atualizando" o lugar do rural na chamada sociedade contemporânea. Tento compreender como a mulher é representada, bem como elas mesmas se identificam nesse contexto. Essa pesquisa evidencia ainda como as mulheres têm demonstrado ser os principais agentes pedagógicos na construção da resistência, na busca de preservar seu nodo de vida/ruralidade.

Atualmente, se tem presenciado, na retórica da maioria dos políticos que a participação das mulheres deva ser importante. No entanto, não se vê políticas serem implementadas, uma vez que estas demandam custo esbarram diretamente na privatização dos serviços públicos e de forma indireta nas desigualdades sociais, e por fim, na inviabilidade do Estado neoliberal. É nesse contexto de emergência da "participação da mulher" que as necessidades destas têm ganhado espaço no discurso/mídia que o governo, estimulado pelo Banco Mundial e Agencias Internacional, de fomento a pesquisas, tem privilegiado análises fragmentadas, acríticas com foco na concessão de direitos às mulheres e não nas contradições geradas pelo desenvolvimento do capitalismo. Essa prática por si só tem corroborado para que as mulheres que antes eram invisíveis nas pesquisas acadêmicos agora aprecem de forma parcial e sem relação com as formas materiais de existência - mínimos vitais - e tão pouco com os nexos constitutivos do homem e da própria história que os homens fazem.

Nesse sentido, as contradições aqui apresentadas partem da observação e análise do cotidiano de mulheres que vivem no 'campo', por acreditarmos que,

a cotidianidade desvenda a verdade da realidade, pois a realidade, à margem da vida de cada dia, seria uma irrealidade transcendente. Do mesmo modo, porém, a esconde: a realidade não está contida por certo aspectos determinados e de forma mediada.(...) Separada da história, a cotidianidade é esvaziada e reduzida a uma absurda imutabilidade; enquanto a História, separada da cotidianidade, transforma-se em um colosso absurdo impotente. (NORONHA, 1986, p.137).

Dessa forma, analisou-se o cotidiano das mulheres no/do assentamento a fim de identificar o sentido de ruralidades ai encontrado. Identificar quem são os atores do meio rural da região sudoeste e como estão produzindo novas ruralidades, no contexto de modernização pela qual tem passado essa região nos últimos tempos. 


\subsection{Ruralidades como fio condutor de análise}

O uso no plural, aqui adotado para a categoria analítica 'ruralidades' está sendo empregado por exprimir mais adequadamente a diversidade de processos e arranjos em curso no mundo rural. Assim, o significado de ruralidades está sendo utilizado como os diferentes modos de viver, que preserva uma raiz rural, por isso, independe da territoriedade. Na verdade, com a intensificação dos processos de globalização e modernização as fronteiras entre rural e urbano, também são recriadas, uma vez que, fatores sócio-culturais são muitas vezes mais expressivos do que fatores como tecnologia e espaço geográfico. Há pessoas vivendo na considerada urbanidade, mas que conservam consigo, sua ruralidade. Dessa feita é que empregamos rualidades no plural, entendendo, que a ruralidade de uma população ribeirinha, por exemplo, difere da de uma população quilombola.

Portanto, não há como negar que existam diversas ruralidades, e estas independe do território em que a pessoa esteja, pois já faz parte constitutiva da pessoa, tornou-se um hábitus. Isso equivale afirmar que a constituição subjetiva dos sujeitos não se desfaz ao bel prazer do que se queira ou se impõe, e mesmo em razão do lugar geográfico em que esse sujeito possa estar sendo obrigado a viver. Entendemos por ruralidades, um modo de vida, uma sociabilidade de raízes rural, que nesse.

conjunto de reflexões nos leva a pensar a ruralidade como um processo dinâmico de constante reestruturação dos elementos da cultura local com base na incorporação de novos valores, hábitos e técnicas. (CARNEIRO: 1998, p. $61)$.

Tais particularidades são preservadas pela ação de atores sociais, que vivem em determinada ruralidade. Atores estes que resistem de certa forma ao avanço nefasto do capitalismo, e na ação de resistir, criam algo novo, por isso, ruralidades é algo dinâmico. Ao assumir a ruralidade como uma construção social no conjunto societário em que homens e mulheres se fazem e fazem sua cultura, não se pode correr o risco de mais uma vez na história, considerar as ruralidades como suporte e/ou oposição ao urbano. Essa dicotomia apresentada oficialmente contribuiu para que se fomentasse a idéia do rural como inferior, atrasado, cafona, entre outras definições pejorativas. Diante deste contexto, o rural ficou durante anos em situação desfavorável não só nos discursos promovidos no espectro de "modernização" do país, mas o que é pior acabou ficando incorporado no senso comum e sendo verdade.

A relação entre rural e urbano no âmbito da modernidade, foi sendo sistematicamente tencionada por um tipo de concepção que valorava positivamente o urbano como locus privilegiado de realização do que é moderno/progresso, o que o colocava como sonho idealizado de realização tanto pessoal quanto familiar e mesmo nacional. Concomitantemente, o rural era apresentado negativamente como locus do tradicional/atrasado devendo ser refutado e abandonado inclusive da subjetividade. Se antes o rural era tido como algo atrasado, pejorativo, hoje já encontramos discursos que carregam uma outra visão desse rural, a maioria agora sustentada pela mesma lógica capitalista, que vê no rural uma saída para todos. Essa saída que vai dos sentidos estritamente subjetivos que imprimem os mais favorecidos economicamente, que vão desde fuga da violência urbana até questões ambientais (busca de tranqüilidade, ar puro, alimentos orgânicos, entre outras) já para os menos favorecidos o campo se apresenta como uma 
objetiva, ou seja, o campo é visto como possibilidade de fuga do desemprego e da falta de moradia e da fome produzidos no urbano.

Portanto, uma atenção redobrada permite perceber que o capitalismo utiliza o discurso de acordo com os interesses de grupos no poder e, no limite, faz desse discurso ora desvalorativo do campo/rural e ora valorativo, dependendo dos interesses em jogo naquele momento. Assim, no caso brasileiro, se durante o século XX provocou-se um êxodo rural, neste século presencia-se uma tentativa do inverso, um êxodo urbano.

A sociedade brasileira parece ter hoje um olhar novo sobre o meio rural. Visto sempre como fonte de problemas - desenraizamento, miséria, isolamento, currais eleitorais etc - surgem, aqui e ali, indícios de que o meio rural é percebido igualmente como produtor de "soluções". (WANDERLEY: 2001, p.31).

Assim, nas diversas soluções que se apresentam, do/para o rural surgem; casa de campo, hotel fazenda, spar rural, pesque e pague, turismo rural, estâncias hidrotermais, eco turismos, esportes campestres, entre outros. Tudo isso, "prima" uma retórica na busca da melhoria da qualidade de vida, preservação da natureza, contato com ar puro, etc. Mesmo nessa nova forma de enxergar o campo, gerada pelas novas relações capitalistas que se propõem a também "produzir" o rural, ainda assim, o "mundo rural" resiste e mantém particularidades históricas, sociais, culturais, ecológicas" idem, p.32. A distância física e social entre habitantes do urbano e do rural está sendo progressivamente diminuída, neste contexto de relações reelaboradas. Dessa forma, o conceito de ruralidades é o que nos permite compreender a relação entre modernização e resistência que vem ocorrendo nesse processo de (re)elaboração e (re)significação do mundo rural, seja ela individual ou coletiva.

Por que então mesmo já fazendo parte do ideário burguês o rural parece tão invisível às políticas públicas, às pesquisas e estudos regionais? Este artigo não tem a pretensão de responder a este questionamento, mas destacar conforme Queiroz (1972), que no Brasil os estudos de Sociologia Rural têm polarizado as relações rural-urbano. Tal postura deve ser modificada se se quer produzir uma Sociologia Rural que dê conta das contradições e das múltiplas determinações constituintes da realidade que se diversifica a ser (re) produzida. Esta polarização ainda se faz presente, embora no discurso politicamente correto tenha se alterado sutilmente. Havendo a necessidade de pesquisas que desvelem as relações de resistência tanto individual quanto coletivas que a tessitura social imprime e evidencia.

Nos estudos de Sociologia Rural, no Brasil, ainda segundo Queiroz, encontram basicamente duas vertentes; uma que considera o desaparecimento das sociedades rurais numa hegemonia da modernização, e outra que observa o processo de modernização, mas, considera que, o mundo rural não se reduz à homogeneização da sociedade contemporânea. Na segunda vertente considera-se que há particularidades de modos de vida que permitem que sejam observadas permanências, resistências, reconstruções. Esse movimento são processos sociais que dão especificidade aos modos de viver que é o que vêm sendo definido como uma categoria analítica ruralidades.

Esta reflexão privilegia a segunda abordagem, por entender que qualquer reflexão sobre as ruralidades na atualidade exige o re-conhecimento do rural, nas suas imbricações com o urbano, uma vez que estes não podem mais ser entendidos como separados por territórios, mas sim corelacionados, ou seja, existe rural no urbano, assim como urbano no rural. Assim como afirma 
Wanderley (2001), que embora haja transformações profundas ocorrendo no meio rural devido o processo de modernização que tem sofrido o rural não se 'perde' nesse processo; ao contrário, reafirma sua importância e particularidade apresentando-se como um espaço social que requer análises que identifique as formas de resistência que aí estão ocorrendo.

\title{
1.2 Resistência à modernização
}

O processo de modernização brasileira tornou-se objeto de estudo e de interesse de pesquisadores nos últimos tempos. A maioria desses trabalhos segue um viés destrutivo, apontam a homogeneização como fato acabado e destaca o lado destrutivo (rios e mananciais destruídos, cerrados devastados, postos de trabalhos tomados por máquinas). Não se quer aqui afirmar que tais denúncias não sejam fundamentais, mas, que também é importante destacar que transformações econômicas afetam os sujeitos e, além de alterar sua cotidianidade imprime-lhes um saber gerado na e pela ação de resistir. Na luta cotidiana pela preservação do modo de vida e da própria produção material de existência, mulheres e homens buscam (re) arranjos adaptativos. É justamente desse viés que aqui nos ocupamos.

A modernização da região sudoeste foi um processo, e como tal, um campo de disputa e resistência, entre dominantes e subordinados, que viram na modernização algo que não era criação deles e que nem emergia dos seus mundos. A modernização trás a tona interesse conflitantes, nesse ambiente de trabalho e exploração, há também resistência a esta exploração.

\begin{abstract}
É importante considerar que "campo" não está passando por um processo único de transformação em toda sua extensão. Se as medidas modernizadoras sobre a agricultura foram moldadas no padrão de produção (e de vida) urbano-industrial, seus efeitos sobre a população local e a maneira como esta reage a tais injunções não são, de modo algum, uniformes, assim como tais medidas não atingem com a mesma intensidade e proporções as diferentes categorias de produtores. (CARNEIRO: 1998, p.53)
\end{abstract}

Embora a vida dessas pessoas esteja em permanente mudança, não há uma alteração por completo. A maioria dos estudos realizados até aqui apontam que as pesquisas ou são feitas discutindo o processo de modernização analisando a camada mais abastada da população por ser nela que se acham mais evidentes as alterações técnicas e tecnológicas, não há um olhar aguçado para os que se rebela, mesmo de forma calada ou mesmo aqueles que o fazem sem saber contra quem ou o quê, mas mesmo assim, rebela, em defesa de seus costumes e seu modo de vida. Essa constatação evidencia que no caso brasileiro também é possível observar que ocorre o que foi percebido por Gramsci:

(...) essa filosofia não era apenas a apropriação de um individuo, mas provinha de experiências compartilhadas no trabalho e nas relações sociais, estando implícita na sua atividade e na realidade, unindo-o a todos os companheiros de trabalho na formação pratica do mundo real [...] Assim as duas consciências teóricas podem ser vistas como derivadas de dois aspectos da mesma realidade: de um lado, a conformidade com o status quo, necessária para a sobrevivência, a necessidade se seguir a ordenação do mundo e de jogar de acordo com as regras impostas pelos empregadores, os 
fiscais dos pobres etc. De outro lado, o "senso comum", derivado da experiência de exploração, dificuldades e repressão compartilhada com os companheiros de trabalho e os vizinhos, que expõe continuamente o texto do teatro paternalista à crítica irônica e, com menos frequiência, à revolta. (CHAUI:1994, p. 20)

Algumas análises vêem a sociedade como se fosse desprovida de vida, de valores, de visões de mundo que resistem ainda que não constituam uma coletividade, apresentam a capacidade de consciência, que transformam situações geradas pelas condições sociais em um saber social, critico.

Diante dos que almejam controlar e oprimir há os que buscam justamente pelo oposto, adquirem uma universalidade própria, desconhecendo fronteiras de não serem oprimidos e não serem controlados. Os sujeitos aqui analisados, não estão num vazio histórico-cultural isolado do social, pelo contrário, são sujeitos determinados em situações determinadas, que fazem sua própria história, diante de situações dadas, mas que constantemente se rebelam e reagem diante do que lhes é imposto e em muitos, resistem (re) significando ordens, imposições e coações que imprime nos sujeitos um novo saber um saber social, gerador de novas ações pedagógicas.

Por saber social entendo o conjunto de conhecimentos e habilidades, valores e atitudes que são produzidos pelas classes, em uma situação histórica dada de relações, para dar conta de seus interesses (...) trata-se de um saber que serve de instrumento de organização e luta. (...) Afinal todo saber corresponde a determinados interesses e, por isto, contém nele mesmo uma questão de poder e de dominação. (GRZYBOWSKI: 1984, p.50).

Assim, o saber também resulta da experiência de resistência e não da simples carência, como as vezes se quer fazer acreditar. A resistência resulta da conscientização da condição vivida pelo sujeito. Da exploração à compreensão de suas condições, o espaço é pequeno. Geralmente, é a mulher quem primeiro sente à privação, a falta de alimentos na panela e o que isso acarreta em sua família. Neste sentido, parece ser a mulher, por ser o sujeito que defronta em sua cotidianidade com a concretude das condições materiais de existência e é capaz de conscientemente agir nele, buscando transformá-lo em algo mais justo.

Com a intensificação do processo de modernização a relação entre campo e cidade tem passado por uma troca, o campo vem para a cidade e a cidade vai para o campo. A tecnologia que chega no campo interfere no modo de vida dos moradores rurais. Assim como as pessoas que vão para cidade não abandonam de toda a sua cultura, ela permanece imbuída na pratica cotidiana. Não se pode pensar mais a relação campo cidade como separados e sim como uma bi-implicação, uma relação dialética. Esses dois espaços social-geográficos não estão mais em oposição e sim relacionados. Essa interação deve ser entendida nos diversos aspectos econômico, cultural, entre outros, uma vez que independentemente do lugar em se que esteja carrega-se valores, cultura, práticas e visões de mundo as quais foram incorporadas ao longo da vida e que compõem as ruralidades. 
No caso das questões relacionadas ao campo, por exemplo, o que se pode ver de mais revolucionária e radical forma de resistência é tratar a terra como valor de uso e não como valor de troca. Ao agir assim, os sujeitos se põem contra o processo de expansão do capital, à medida que adquirem consciência de suas ações eles inauguram algo ex novo, ou seja, (re) significam práticas vivenciadas de outras formas. As idéias de modernização apareceram pensadas para o urbano, mas acabaram influenciando no rural. No Brasil, como nas demais partes do planeta se tem ilhas industrializadas, contrapondo-se a oceanos de pobreza que abrigam excluídos e mesmo assim, como no caso de Goiás o que financia e mantém a modernização é a produção de base agrária.

Dessa forma, é possível afirmar que no limite, a resistência à modernização no sudoeste goiano tem se dado de múltiplas formas e entre elas destaca-se aqui a participação da mulher do campo que na luta pela resistência adquire conhecimentos, imprime um novo saber social a si mesma e às novas gerações produzindo um saber que não possuíam antes. Esse saber produzido se interpõe à expansão do processo de modernização capitalista, nesse sentido, a modernidade continua a se surpreender com a resistência e o saber social produzido no e pelo mundo rural.

\subsection{A mulher em processos de novas ruralidades}

Desvendar o papel da mulher em processos de novas ruralidades não é tarefa fácil, uma vez que esse processo é algo dinâmico e não se dá só no espaço rural. Para efeito ilustrativo de análise, tomemos como exemplo um assentamento na região sudoeste, criado no contexto de modernização.

Tal assentamento denominado de Santa Rita, distante 30 km do município de Jataí, fruto de um acampamento da própria região, criado em 1995, cujas principais atividades econômicas são bovinocultura de leite e uma minoria agricultura (soja, milho e arroz), possui 23 famílias, cada qual com lotes em média de 30 hectares e que atualmente não tem obtido liberação de recursos financeiros junto aos órgãos de fomento. Das 23 famílias que acamparam lutando pela posse da terra, seis a repassaram adiante. Assim, a composição atual do grupo se constitui de seis famílias que obtiveram o lote depois.

A síntese do perfil das mulheres entrevistadas aponta que mais de $90 \%$ delas são casadas, possuem entre 35 e 43 anos, $85 \%$ sabem lê, $87 \%$ se consideram proprietárias do lote, mais de 95\% trabalham na lida da terra, $100 \%$ freqüenta algum tipo de local comunitário, no próprio assentamento participando e atuando na preparação de cultos ecumênicos que ocorrem por lá uma vez por mês, ou orações de terço e/ou em festas e eventos do assentamento, no núcleo comunitário ou nas casas das assentadas.

Todos homens e mulheres vieram de famílias de origem rural, e já trabalhavam com a terra antes mesmo de se tornarem assentados. Cerca de $80 \%$ há mais de 20 anos. Ambos atribuem um valor grande a terra e a vêem como fonte de subsistência, somente cerca de10\% possui outras fontes de renda além da terra (aluguel da casa que ficou para trás na cidade ou aposentadoria). As rendas das famílias variam entre um e três salários mínimos. Evidenciando que a população desse assentamento além de terem uma forte relação com a terra, são sujeitos que estariam de um jeito ou de outro, excluídos da vida urbana.

Embora haja nas residências, antena parabólica, televisão, geladeira, telefone celular, aparelho de som, entre outros, as famílias preservam suas ruralidades, seja em pequenos detalhes, não abrindo mão de um café moído na hora ou de manter a carne preservada na banha, mesmo 
tendo a geladeira do lado. Observa-se que muitos regem suas atividades seguindo as mudanças da lua, preservam os quintais cuja responsabilidade total cabe à mulher. Esse é um pouco do cotidiano do assentamento Santa Rita.

Historicamente a mulher tem sido destinada à esfera privada e o homem a pública, o processo de modernização interferiu nessas duas esferas, embora a ruptura com a tradição, não tenha sido de toda rompida, uma vez que, compreende-se tradição como um processo em ação, sempre há a possibilidade da emergência constante de novos valores e atividades. As mulheres desse assentamento, freqüentemente vendem seus excedentes na feira municipal do município de Jataí, estão, portanto, relacionando-se com a esfera pública.

A tradição é um processo dinâmico onde maneiras tradicionais de estabelecer relações sociais entram em conflitos que podem ou não gerar novos valores. As mudanças ocorridas nas relações sociais das famílias do sudoeste goiano não são hegemônicas,

No que se refere à tradição, passados de geração a geração, verifica-se um predomínio do papel da mulher quanto ao conhecimento sobre cuidados com a saúde, preparando chás, pomadas, xaropes, garrafadas para os mais variados males como: dores de barriga, de dente, de cabeça, gripes, e outros. Mesmo que às vezes combinados com algum remédio industrializado, adquirido na cidade. Estes tradição aprendida de seus antepassados, em sua maioria é fruto de sues quintais, onde este sim representa o mais alto grau de ruralidade em um assentamento. Ali se cultiva os alimentos/medicamentos para manter a família. O quintal assim compreendido representa uma continuação de suas culturas, no novo, mas que no fundo completa suas ruralidades.

Assim, embora a vida social no campo esteja em permanente mudança e a mobilidade seja considerável, essas mudanças ainda não chegam ao ponto em que se admita que cada geração sucessiva tenha um horizonte diferente da geração anterior. A modernização não rompe com a tradição, mesmo que esta possa está subsumida em determinadas situações.

$\mathrm{Na}$ preservação dessa tradição da mulher na esfera privada observa-se no assentamento Santa Rita que são elas as principais responsáveis pela unidade de produção familiar, no cultivo dos quintais, casos em que ela domina e mantém limpo e cercado, geralmente é o espaço permitido as crianças menores brincarem.

A mulher é também a total responsável no processamento da produção do leite, fabricando manteiga, queijos, coalhadas, doces, bolos e biscoitos, como também no processamento de outros alimentos, como do milho e das pimentas, para as conservas e das frutas destinadas aos doces e geléias.

As tensões entre tradição e modernidade; entre afirmação da individualidade e convivência coletiva; entre o público e o privado, espaços cindidos em suas formas de organizar a reprodução da vida cotidiana; e entre os significados e as conseqüências dos pertencimentos de gênero - ser homem ou mulher - encontram na organização da vida doméstica e nas relações familiares intensos locais de experiência dado que constituem espaços privilegiados de vivencias de interação afetiva e de condução da vida cotidiana, marcada por conflitos, tensões e também por prazeres. Essa experiência é fortemente vivenciada entre as mulheres do assentamento visto que ao mesmo tempo em que fabricam as geléias, doces e conservas para vender não se furtam de oferecê-las aos visitantes que lhes agrade como símbolo de amizade.

É, portanto, a mulher a principal responsável por colocar em prática, saberes adquiridos com outras gerações. É ela que tem garantido a sociabilidade no mundo rural, atuando no espaço público e no privado. Atuando junto a família, na vizinhança, na religiosidade, na feira. Ela silenciosamente faz as articulações e 'costuras' do tecido social da unidade familiar e da 
comunidade. Portanto, é possível afirmar que a mulher produz ruralidades à medida que atua no seu cotidiano, resolvendo suas demandas e encaminhando soluções e mantendo a solidariedade orgânica que elas estabelecem com as vizinhas que se tornam seus pares e assim garantem a sociabilidade e a solidariedade no assentamento.

\section{Considerações finais:}

A inovação-industrialização, globalização, modernização é mais evidente na camada superior da sociedade, mas como ela não é um processo tecnológico/social neutro e sem normas, e sim a inovação do processo capitalista, é quase sempre experimentada pelos trabalhadores como uma exploração, como expropriação de direitos, de perca de suas tradições, ou a destruição violenta de seu modo de viver.

O que se verifica no decorrer da pesquisa é que a mulher no campo da produção tem sido precursora dentro da unidade familiar, da manutenção da tradição. As mulheres, na sua maioria, são as responsáveis por manter a religiosidade no seio das famílias, participando de terços nas vizinhanças.

Embora em outros assentamentos da mesma região haja maior participação das mulheres nas cooperativas, sindicatos e associação, ou seja, uma vivencia na esfera pública, neste o papel delas é mais evidente nos espaços de domínio privado, como os da religião, da família, da vizinhança.

As famílias pesquisadas se caracterizam como um segmento social homogêneo, pertencente à ampla categoria social de pequeno produtor, diferentes lógicas existem nos lotes agrícolas, desde as lógicas regidas somente pela demanda da família, satisfação dos mínimos vitais (a maioria), até àquela em que a produção se norteia por uma lógica de mercado capitalista, no caso das que produzem soja (minoria).

Nessas famílias a relação com o meio rural é estabelecida principalmente pelas tradições transmitidas pelas gerações passadas, e grande parte dos/as filhos/as pequenos vivem estas relações de sociabilidade com o meio rural, embora quando vão pra escola perdem um pouco esta sociabilidade rural.

Entretanto, o principal parâmetro que caracterizou tais famílias foi encontrado a partir da trajetória de vida dos responsáveis pela unidade produtiva. Os que passaram ou não pelo processo de luta pela terra. Os que não lutaram pela terra (6 famílias) produzem prioritariamente pra o mercado (soja) e secundariamente para a subsistência, já os integrantes da luta (17 famílias), produzem prioritariamente para a família e só secundariamente para o mercado.

O conceito de ruralidades consegue explicar o fenômeno de resistência que se operou no cotidiano das pessoas que foram arrancadas do campo e levadas para as cidades e que insistiram e insiste em manter sua origem rural, essa relação com o rural enraizou em nossa cultura fazendose representar nas diversas formas de expressão que é utilizada para demonstrar sentimentos humanos, como é o caso da música, das comidas típicas, da ornamentação com plantas e com artesanato, entre outras formas de expressar o rural. Há atualmente em curso uma revalorização do rural não porque se percebeu a sua importância e sim porque em geral vê-se nele, uma fonte explorativa/lucrativa desse anseio por viver e conservar o rural. 


\section{Referencia bibliográfica}

CARNEIRO, Maria José. Ruralidades: novas identidades em construção. In Estudos Sociedades e Agricultura, $\mathrm{n}^{\circ}$ 11, 1998.

CHAUÍ, Marilena. Raízes teológicas do populismo no Brasil: teocracia dos dominantes, messianismo dos dominados. In Os anos 90: política e sociedade no Brasil. São Paulo: brasiliense, 1994.

GRZYBOWSKI, Cândido. Esboço de uma alternativa para a educação no meio rural, in: Contextos \& Educação, nº 4, Ijuí, FUI, 1984.

NORONHA, Olinda M. De camponesa a "Madame": trabalho feminino e relações de saber no meio rural. São Paulo: Loyola, 1986.

QUEIROZ, Maria Isaura P. Do rural e do urbano no Brasil. In: SZMRECSANYI, Tamás; QUEDA, Oriovaldo (Orgs.). Vida rural e mudança social: leituras básicas de sociologia rural. São Paulo: Nacional, 1972.

THOMPSON, E. P. Costumes em comum: estudos sobre a cultura popular tradicional. São Paulo: companhia das letras, 2002.

WANDERLEY, Maria de Nazareth B. A ruralidade no Brasil moderno: por um pacto social pelo desenvolvimento rural. In: GIARRACCA, Norma. (Comp.) Una nueva ruralidad en América Latina? Buenos Aires: CLACSO/ASID, 2001. 